\title{
Multilevel power converter for grid-connected residential solar PV system
}

\author{
Léon T. Njouakoua ${ }^{1}$, Atanda K. Raji ${ }^{2}$ \\ ${ }^{1}$ njouakoua@yahoo.fr, ${ }^{2}$ rajia@cput.ac.za \\ Faculty of Engineering, Department of Electrical Engineering, \\ Cape Peninsula University of Technology, Bellville, South Africa
}

\begin{abstract}
This paper presents a multilevel power converter for non-standalone residential solar panel system. A single-phase three level photovoltaic inverter diode clamped multilevel inverter topology is designed and built to demonstrate the benefits and advantages of multilevel inverter in terms of output power quality. Pulse width modulations signal is generated using the microcontroller ATmega328 which generates pulse signals to control all the four switching devices of the inverter. To enable the photovoltaic inverter to be synchronized with the utility grid, a phase locked-loop is used. In addition, a closed loop feedback voltage control is designed to ensure the stability of the inverter input voltage so that the current and the voltage injected into the grid are sinusoidal and remain constant with rapid changes in the prevailing atmospheric conditions.
\end{abstract}

Keywords: Grid-connected residential solar photovoltaic system; multilevel power converter; Phase lock loop; solar photovoltaic system.

\section{Introduction}

The production of electricity will become a big challenge for the next coming generation because firstly the industrial market is growing days after days and secondly we do have a huge increase of the world population each and every second. These two given occurrences will then result into a massive increase of the electricity demand putting pressure on the electricity suppliers. A lot of technologies have been used to generate or to realize energy conversion from one source of energy to electrical energy. The most explored technologies are hydroelectric technology, wind system technology, nuclear technology, and photovoltaic technology. Due to the shortage of fossil fuels and the negative impact of some energy production technology on the environment, the advancement of power electronics introduces a new class of power converters known as multilevel converters in high and medium power voltages applications so that it can assist the electrical grid to solve this issue of high electricity demand [1]. Multilevel inverters or converters have been recently used in many industrial applications, furthermore renewable energy such photovoltaic system technology can interface with a multilevel converter system in high, medium and low power application [2].A reduction of switching harmonics in the inverter output waveform without any unnecessary increase of the switching frequency of the converter is one of the important advantages of a multilevel converter [3]. Other advantages that can be drawn from multilevel converters are: a reduction of voltage stress on power electronic semiconductors devices;

ACRID 2017, June 20-21, Victoria Falls, Zimbabwe

Copyright $(0) 2017$

DOI 10.4108/eai.20-6-2017.2270892 
switching loss reduction; and the ability to generate multiple levels of inverter output voltage also improve the voltage quality of the output power. A smaller size of output AC filter is also realized by use of multilevel converter topology.

\section{Photovoltaic System}

For the past decades, worldwide growth of photovoltaic system technology has been moving as an exponential curve [4] since the world's power energy demand is increasing.

Private operators who are using photovoltaic technology have some important goals to achieve like operating a system which has long life time, high efficiency and good environmental condition. Beside those goals, it might happen that the private operators would like to supply excess generated energy to the electrical network of its area (a local electrical grid); therefore important factors need to be fulfilled before any connection to the grid is imitated such as interconnection requirements, synchronization conditions, power quality compliance, safety and protection requirements, acoustic noise limitations and electromagnetic compatibility.

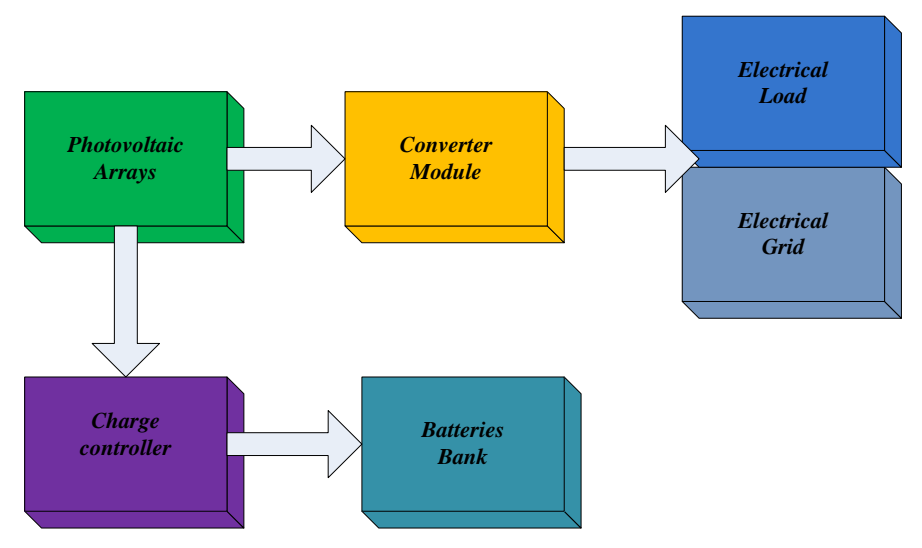

Fig. 1. Illustrates a block diagram of a stand-alone or grid connected energy system.

In Fig. 1, the block having the label of photovoltaic arrays represents the primary source of energy which will generate the electrical energy that can be stored in the batteries bank through a charger controller block. Using converter module block, the generated power can be transformed to fulfill the needs of the electrical load and the electrical grid.

Photovoltaic system can be designed and mounted so that they can meet electrical requirement. Thus, they can be grid-connected or standalone [5].

\subsection{Photovoltaic Modules or Solar Cells}

The solar cell is the basic unit of a photovoltaic system that converts photons from the solar light into electricity [6].Bright light reflected on the solar cell manufactures both current and voltage to generate electric power [7].A photovoltaic cell can be modelled as a parallel 
connection circuit of a current source and a rectifying diode. The "I-V" characteristic curve obtained from that circuit is portrayed by the Shockley solar cell equation 1 given below [8]:

$$
I=I_{p h}-I_{o}\left(e^{\left[\frac{q\left(V+I R_{s}\right)}{n K_{B} T}\right]}-1\right)-\left(\frac{V+I R_{s}}{R_{s h}}\right)
$$

Where:

$V$ : voltage across the output terminal in volts

$\boldsymbol{I}_{\text {ph: }}$ : photo generated current in Amperes

I: output current in Amperes

$\boldsymbol{R}_{\text {sh }}$ : shunt resistance in ohms

$\boldsymbol{R}_{\text {s: }}$ series resistance in ohms

n: diode equality factor

$\boldsymbol{I}_{\boldsymbol{o}}$ : reverse saturation current in ampere

q: elementary charge

$\boldsymbol{K}_{\boldsymbol{B}}$ : Boltzmann's constant

T: absolute temperature

An equivalent circuit of a non-ideal solar cell can be drawn using PSIM as shown in Fig.2:

\section{Equivalent circuit of \\ a solar cell using PSIM}

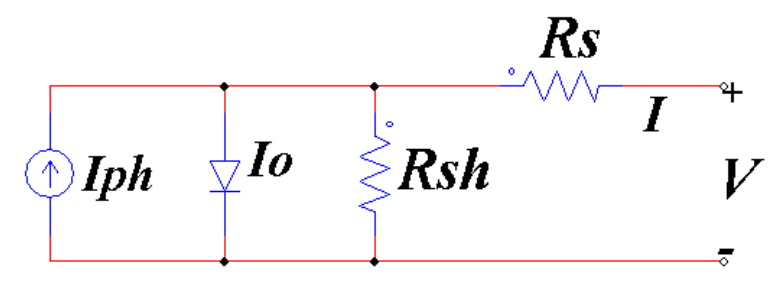

Fig. 2. Equivalent circuit of a non-ideal solar cell.

\subsection{Maximum Power Point Tracking of Photovoltaic Modules}

Maximum power point tracking is an important factor for photovoltaic system because it is a technique used to maximize its output power under a given set of weather conditions [9].Many Maximum Power Point Tracking methods have been studied, designed and implemented to allow multilevel converter to automatically extract the maximum power available in the solar cell. Major Maximum Power Point tracking methods have been elaborated in the technical literature such as [10]: 
- Hill climbing method which introduces perturbation of the power converter's duty cycle,

- Approximation of the MPPT through mathematical equation using an intermediate variable method,

- Incremental conductance method

- Constant or fixed duty cycle method.

However for this study, perturb and observe method is implemented through a combination of a boost power converter with closed feedback loop PI control and the PV array modules. The boost converter will adjust the output voltage of the photovoltaic panel and the feedback controller will maintain the output voltage constant under perturbations caused by the changes in the ambient temperature and solar irradiance.

\section{Multilevel Power Converters}

Primary basic concept of multilevel converter is based on the fact of using high power switching devices in series with DC voltage source so that they can realize the transformation of energy by syntheses of set of stairs showing the shape of a voltage waveform. Batteries, renewable energies can be used as DC voltage source in a multilevel inverter. When an increase of the level occurs in a multilevel inverter, lower harmonic content of the output voltage waveform is realized [11].Furthermore, the more the steps or levels of the inverter, the closer the desired output waveform which is a pure sine waveform. The attractive features of a multilevel converter are given below [12]:

- Quality of the set of stairs.

- Voltage sharing mode.

- The turn ON time of the power electronic switches.

\subsection{Multilevel Converters Structures}

Lot of multilevel topologies have been studied and proposed over the past two decades, but only have three different major multilevel converter structures which are listed below [12]:

- The diode clamped multilevel inverter

- Flying capacitor multilevel inverter

- Cascaded H-bridges

\subsubsection{Diode-Clamped Multilevel Inverter}

Illustrated in this section by Fig. 3 below, diode clamped multilevel inverter also known as neutral point clamped multilevel inverter makes use of the voltage blocking diodes. 


\section{One Single leg of 3 level diode clamped inverter topology}

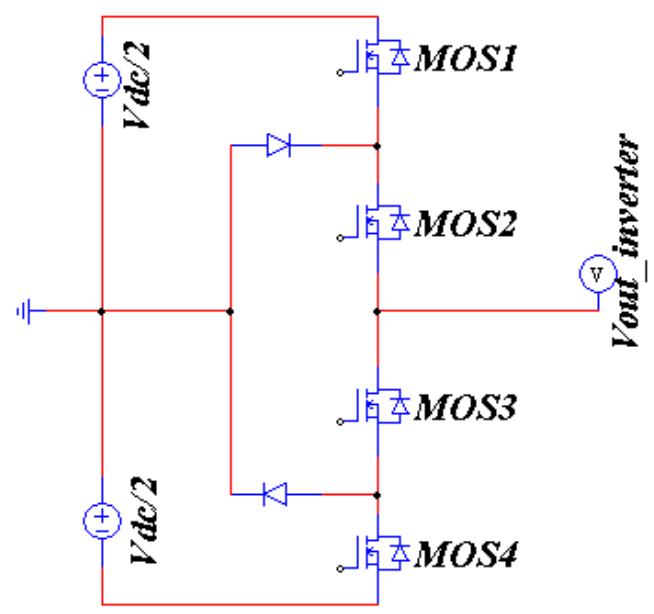

Fig. 3. One single leg of 3-level diode clamped inverter topology.

The same DC-bus is shared in the multilevel inverter; the amount of voltage levels of the inverter will determine the amount of independent voltages sources that will be mounted in series at the input side of the inverter which will also form the neutral point of the inverter [13].

Thus, a given "x-level" neutral point clamped topology will require the following component:

- $\quad$ Number of switching devices $=2(\mathrm{x}-1)$ per leg

- $\quad$ Number of clamping diodes $=(\mathrm{x}-1)(\mathrm{x}-2)$ per leg

- $\quad$ Number of dc sources $=(\mathrm{x}-1)$

\section{Advantages:}

- The same DC-bus is shared in the converter.

- Efficiency is high for fundamental switching frequency.

\section{Disadvantages:}

- Tough real power flow

- Relationship between the bolting diodes number and the level's amount.

\subsubsection{Flying Capacitor Multilevel Inverter}

Flying capacitor multilevel inverter topology is also known as capacitor clamped multilevel inverter topology [13]. It is identical to the diode clamped topology in term of the schematic as shown in Fig. 4. Rather than use clamping diodes as in the neutral point clamped topology, it uses capacitors to keep voltages to the intended set value. 


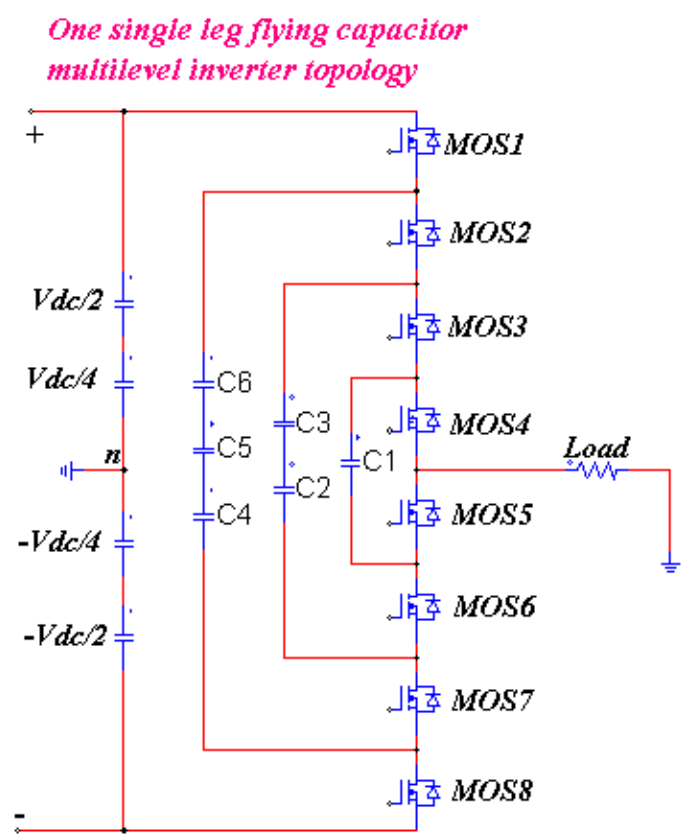

Fig. 4. One single leg of Flying-capacitor multilevel inverter topology.

Thus, a given "x-level" capacitor clamped topology will require the following component:

- Number of clamping capacitor $=(\mathrm{x}-1)(\mathrm{x}-2) / 2$ per leg or per phase

- $\quad$ Number of dc sources $=(\mathrm{x}-1)$

Advantages:

- Power flow control can be realized

- Phase redundancies are present when we have balanced capacitors' voltage levels

\section{Disadvantages:}

- High cost of bulk capacitors

- Voltage level for all of the capacitors is hard to track.

- $\quad$ Poor efficiency

\subsubsection{Cascaded H-Bridges Multilevel Inverter}

Cascaded H-bridges multilevel inverter topology is different from the first two previous topologies discussed in the above sections. It uses cascaded full bridge inverters with independent DC-sources, to manufacture a set of stairs showing the shape of a waveform [14].The alternative output of each individual full-bridge circuit is linked in series in a way that the global output's signal is the sum of the every single bridge circuit's output. Thus, a given "x-level" cascade inverter topology will require the following component: 
- $\quad$ Number of dc sources $=(\mathrm{x}-1) / 2$

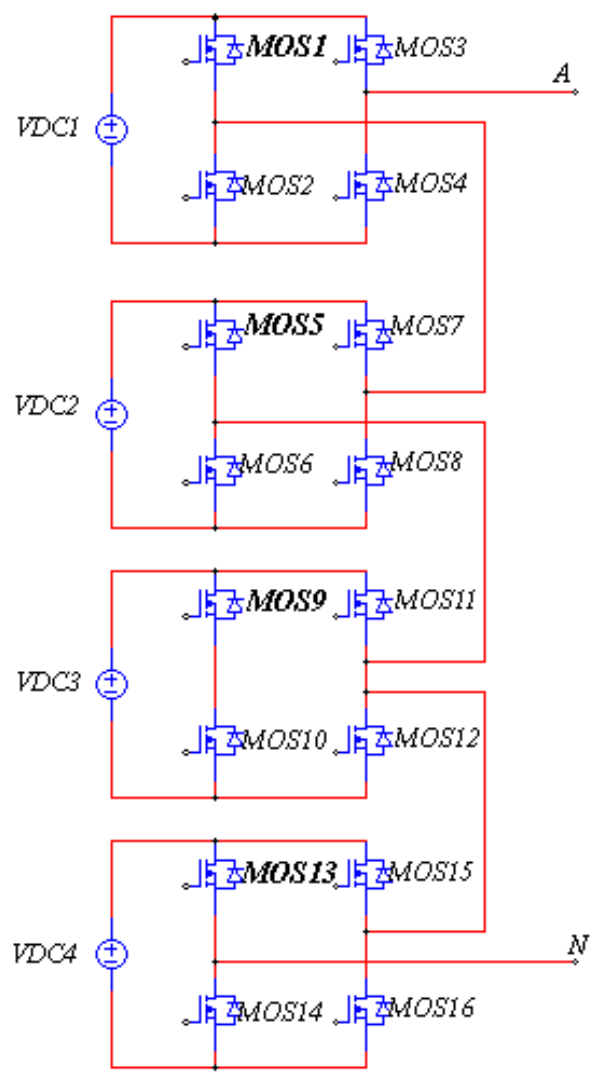

Fig. 5. Single phase structure of a multilevel cascaded H-bridges inverter.

\section{Advantages:}

- The output voltage levels are doubled or two times the DC sources amount is equal to the output stairs number.

- $\quad$ Packing and layout are modularized

\section{Disadvantages:}

- $\quad$ Each single H-bridge requires a separate DC source

- $\quad$ Limitation of applications due to large number of DC sources

Alongside the major multilevel inverter topologies mentioned in the above sections, extra multilevel topologies have been suggested like [12]:

- Mixed-level Hybrid multilevel converter

- $\quad$ Soft-switched multilevel converter 
- Back-to-back Neutral point converter

\section{Multilevel Converters PWM Modulations Strategies}

Major strategies used for multilevel inverter is basically a modified version of the classic one [12].Three multilevel PWM methods are used to design multilevel inverters, there are known as:

- Multilevel carrier-based PWM: which consists of subharmonic PWM, switching frequency optimal PWM.

- Fundamental switching ON frequency method: to lower the total harmonic distortion for synthesized waveforms, selective harmonic modulation method can be used.

- Multilevel space vector PWM

\section{Design of a 3-Leveel Inverter: Diode Clamped Multilevel Inverter Topology}

A neutral point clamped 3-level inverter has been designed and built, because of its high efficiency for a fundamental switching frequency and the possibility of sharing the same DC bus voltage among all the power electronic switches. Some assumptions have been made during the design of this inverter: firstly, we assume that the photovoltaic array automatically search for its maximum power point tracking by implementing the MPPT system with a boost converter under a given temperature and irradiance. Secondly, the limited output current is set at a value of 2 Amperes and we selected a fundamental frequency of 50 Hertz with a switching ON time of half a period to eliminate the 3rd harmonic of the output signal. This will help us to implement the fundamental frequency method which will be used as PWM strategy method for our design. 


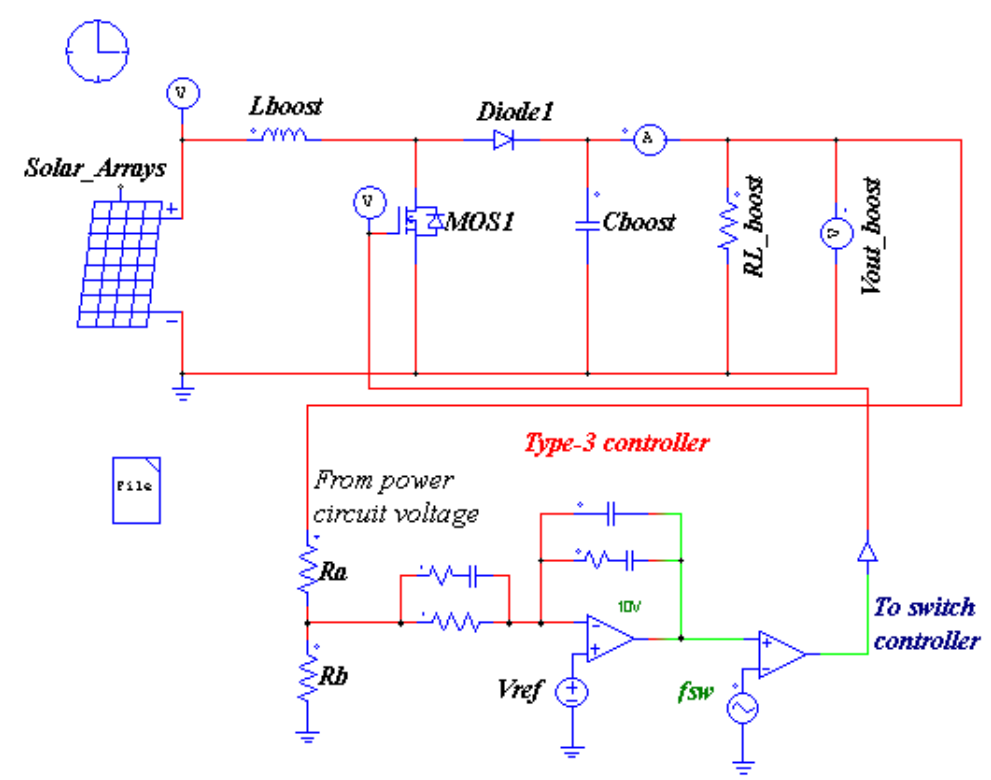

Fig. 6. Implemented MPPT tracking methods using a boost converter.

Considering the output of the boost converter as the input of the 3-level inverter, the electrical circuit can be drawn as shown in Fig. 7:

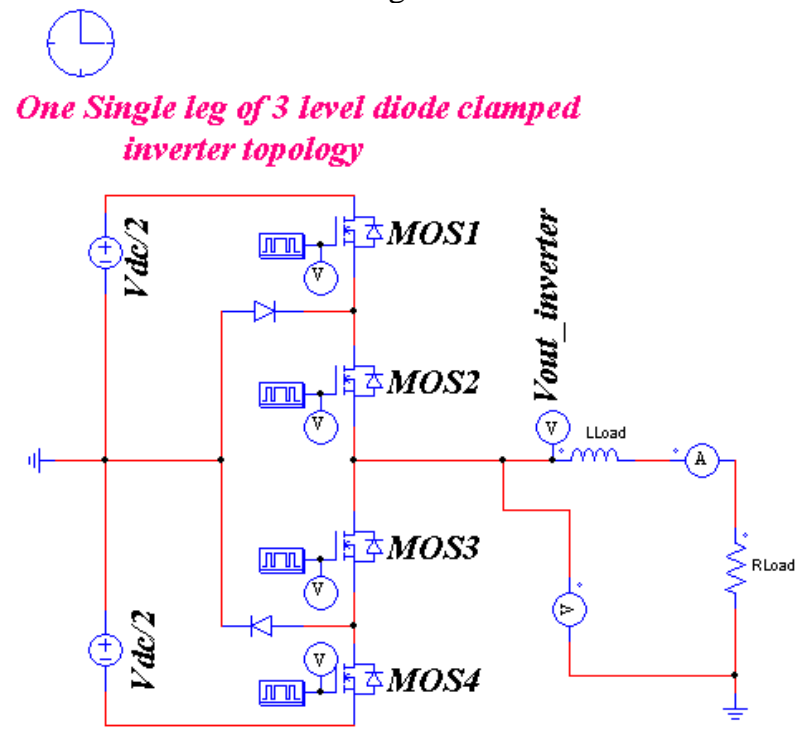

Fig. 7. 3-level diode clamped inverter.

The working process of the above inverter is summarized as follows:

- The output voltage is equal to half of Vdc only if both MOSFET 1 and MOSFET 2 are switched ON together, while MOSFET 3 and MOSFET 4 are switched OFF. 
- The output voltage is equal to zero only if both MOSFET 2 and MOSFET 3 are switched ON together, while the MOSFET 1 and MOSFET 4 are switched OFF together.

- The output voltage is equal to half of -Vdc only if both MOSFET 3 and MOSFET 4 are switched ON. While the MOSFET 1 and MOSFET 2 are switched OFF.

This switching sequence is realized with the help of Arduino Uno board where a pulse width modulation code has been written and uploaded to drive the MOSFETs as indicated in its operational details. The following graphs are obtained during after the simulation process on PSIM:

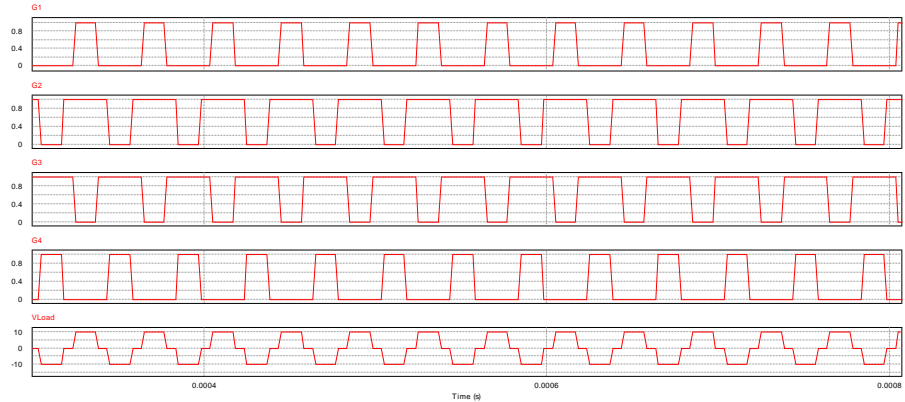

Fig. 8. Expected output and Mosfets gates signal.

Mathematical analysis was used to achieve harmonic elimination in the designed neutral point multilevel converter shown by equation 2 :

Where:

$$
v(t)=V_{o}+\sum_{n=1}^{\infty}\left[a_{n} \cos (n w t)+b_{n} \sin (n w t)\right]
$$

$v(t)$ : instantaneous value of the output voltage

$V_{o}$ : is the DC value of the output voltage

$\boldsymbol{a}_{\boldsymbol{n}}, \boldsymbol{b}_{\boldsymbol{n}}$ : represent the Fourier series coefficients

$n$ : number or order of the harmonic

Thus, the fundamental RMS voltage is calculated using the expression given in equation 3:

$$
\mathrm{V}_{\mathrm{rms}}(\mathrm{t})=\sum_{\mathrm{n}=1}^{\infty}\left(\frac{(2 \sqrt{2}) \mathrm{V}_{\mathrm{o}}}{\mathrm{n} \pi} \cos \left(\mathrm{n} \times \mathrm{t}_{\mathrm{on}}\right)\right)
$$

With:

$t_{\text {on: }}$ is the turn-on time selected to eliminate the third harmonic

Consequently, the RMS output current of the circuit is determined using the expression of equation 4: 
Where:

$$
\mathrm{I}_{\mathrm{rms}}(\mathrm{t})=\frac{\mathrm{V}_{\mathrm{rms}}(\mathrm{t})}{\mathrm{Z}_{\text {total }}}
$$

$Z_{\text {total: }}$ is the total impedance of the circuit

As an illustration, a simulation on PSIM is done to evaluate the elimination or reduction of harmonics in the output signal as shown in Fig. 10:

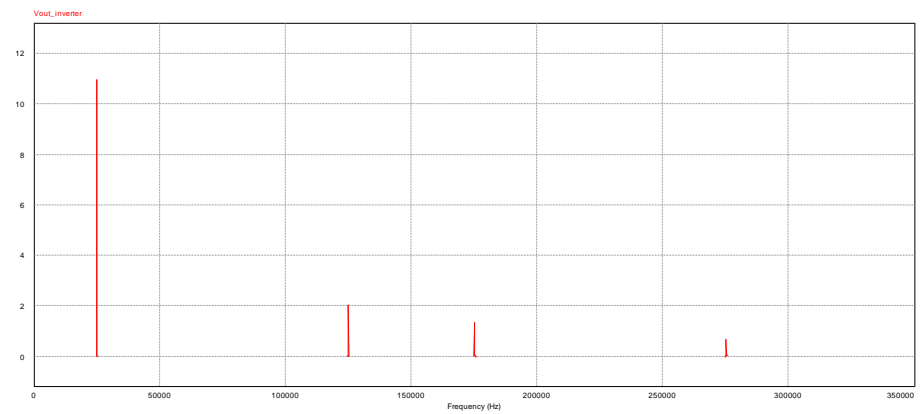

Fig. 9. Fast Fourier analysis on PSIM.

It is observed from the Fast Fourier Transform analysis of the output voltage done using PSIM demo 9.3 that all the even harmonics, third harmonic and tripled harmonics are eliminated.

\section{Phase Locked Loop Controller}

The essential key of the phase locked loop is to trace and match the grid voltage to the power inverter output voltage, even with harmonic's presence. Phase locked loop techniques have been used in the way to ensure that the power converter and public service grid operates synchronously [11].

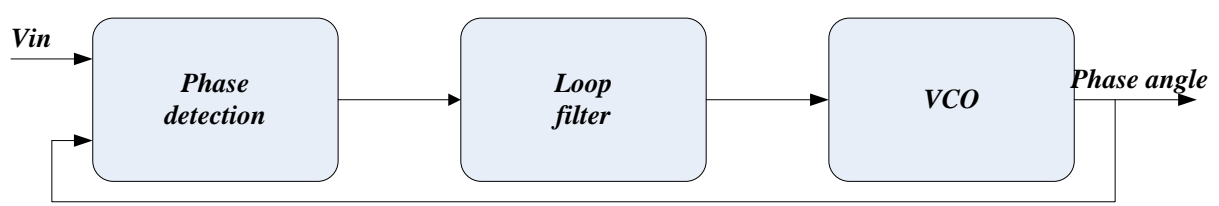

Fig. 10. Closed loop synchronization structure.

\section{$7 \quad$ Practical Design of a 3 level Inverter}

The final design of the inverter has been done using a printed circuit board where electronic components have been placed on a single layer as shown on Fig. 11: 


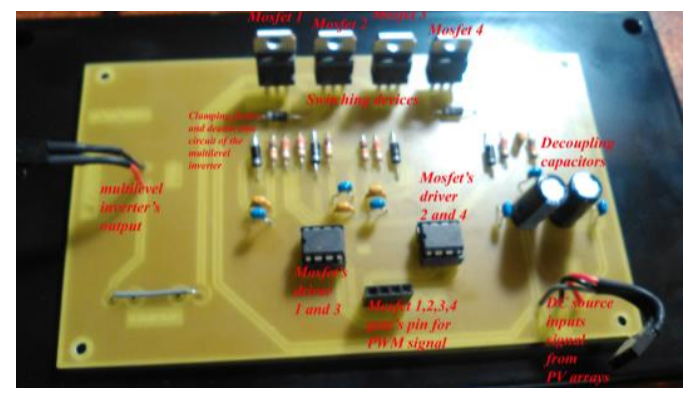

Fig. 11. PCB with components of a 3 level diode clamped multilevel inverter.

The next figure shown as Fig. 12 demonstrates the final populated enclosure of the inverter before its setup and testing in the laboratory:

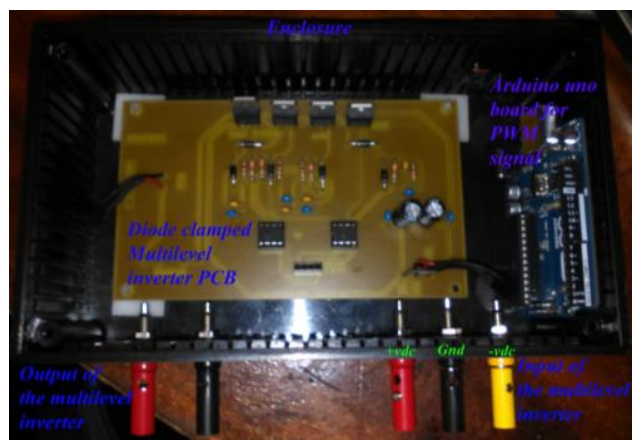

Fig. 12. Final device with its enclosure.

The inverter's output signal is shown displayed on a digital oscilloscope as seen in Fig.13:

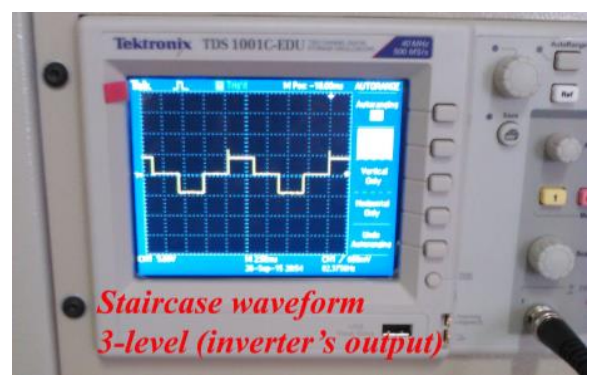

Fig. 13. Output waveform of the designed 3-level inverter.

\section{Conclusion}

The simulation and design of a three level inverter is done using PSIM software which effectively assisted on the evaluation of the total harmonic distortion and the Fast Fourier Transform analysis on the output signal of the multilevel inverter. A comparative review was done on the different major topologies of a multilevel inverter as well as their modulation 
techniques or strategies but only one of them was implemented for this paper. The selection of that PWM method and the inverter's topology relies on the simplicity of the power switching circuit and the ability of controlling the switching devices using basic conventional PWM techniques.

A mathematical approach has been used to achieve harmonic elimination in the neutral point clamped multilevel inverter as shown in equation 2 and equation 3 stated above. The control of harmonic is done by adjusting the value of the switching angle "ton" of the power switching device.

\section{References}

[1]. Pairindra, W., Khomfoi, S.: The enhancement of multilevel converter for coaxial inductive power transfer in low voltage DC power distribution. In: 13th International Conference on Electrical Engineering, Electronics, Computer, Telecommunications and Information Technology, pp. 1--5. ECTI-CON (2016)

[2]. Mishra, R., Mishra, G.: Simulation Model of a Three Phase Multilevel inverter for a Grid Connected Photovoltaic System, http://www.ramauniversityjournal.com

[3]. Deepthi, J., Saxena, S. N.: Study of variation of THD in a Diode clamped multilevel inverter with respect to modulation index and control strategy. In: 2nd International Conference and workshop on Emerging Trends in Technology, International Journal of Computer Applications, pp. 37--42. (2011)

[4]. The Growth of Photovoltaic Solar Around the world, http://www.planeteenergies.com

[5]. Kaundinya, D. P., Balachandra, P., Ravindranath, N. H.: Grid-connected versus stand-alone energy systems for decentralized power. In: A review of a literature, Renew Sustain Energy rev., vol. 13, pp. 2041-2050 (2009)

[6]. Solar cell, http://www.sciencedaily.com

[7]. Solar Cell Structure, http://www.pveducation.org

[8]. Kumar, P.: Organic solar cells: device physics, processing, degradation and prevention. Boca Raton, FL. CRC Press, Taylor and Francis Group (2017)

[9]. Tajuddin, M. F. N., Arif, M. S., Ayob, S. M., Salam, Z.: Pertubative methods for maximum power point tracking (MPPT) of photovoltaic systems. In: a review, Int. J. Energy Res., vol.39, pp. 1153--1178(2015)

[10]. Raghavendra, M., Ramanand, S., Naganagouda, H.: New Grid connected PV system Using reduced switch multilevel inverter and PID controller. In: int. J. Innov. Technol. Explor. Eng. IJITEE ISSN, pp. 2278--3075

[11]. Guo, X. Q., Wu, W. Y., Gu, H. R.: Phase locked loop and synchronization methods for grid-interfaced converters. In: Przeglad Elektrotechniczny., vol.87, pp.182--187(2011)

[12]. Khomfoi, S., Tolbert, L. M.: Multilevel Power converters. In: Power electronics handbook., pp. 451--482(2007)

[13]. Patil, V. Y., Patil, V. V.: Multilevel Inverters. A survey (2015)

[14]. Mittal, N., Singh, B., Singh, S. P., Dixit, R., Kumar, D.: Multilevel inverters: A literature survey on topologies and control strategies. In: 2nd International Conference on power, Control and Embedded Systems, pp. 1--11 (2012) 